\title{
Survival motor neuron (SMN) polymorphism in relation to congenital arthrogryposis in two Piedmont calves (piemontese)
}

\author{
Maria Longeri $^{\mathrm{a} *}$, Tania Perrone ${ }^{\mathrm{a}}$, Graziella Bongioni ${ }^{\mathrm{b}}$, \\ Marco BonA $^{\mathrm{c}}$, Marta ZanOTTI ${ }^{\mathrm{a}}$, Andrea GAlli ${ }^{\mathrm{b}}$ \\ a Istituto di Zootecnica, Faculty of Veterinary Medicine, University of Milan, Italy \\ ${ }^{\mathrm{b}}$ Istituto Sperimentale Italiano L. Spallanzani, Rivolta d'Adda (CR), Italy \\ ${ }^{c}$ Associazione Nazionale Allevatori Razza Piemontese, Carrù $(\mathrm{CN})$, Italy
}

(Accepted 26 February 2003)

\begin{abstract}
The term arthrogryposis refers to a symptom complex that is characterised by congenital limb contractures. Arthrogryposis has been reported in man, in farm animals and in pets. Several forms have been reported to have a genetic origin in man. In Brown Swiss and Holstein Friesian cattle, congenital contractures have been recorded and classified as spinal muscular atrophy (SMA). The survival motor neuron gene $(S M N)$ has been suggested as a candidate gene for SMA. In the last 20 years, the National Association of Piedmont Cattle have recorded arthrogryposis cases. We cloned and sequenced SMN cDNA extracted from the spinal cord samples of two animals: one Piedmont calf showing a severe clinical form of arthrogryposis and one normal Piedmont calf. In the affected calf, more than $50 \%$ of the 5 'end clones showed a ATG > TTG single nucleotide polymorphism (SNP) in exon 1 that should determine a Met $>$ Leu aminoacid change (single point mutation M3L). This mutation is associated with a $9 \mathrm{bp}$ increase length of $5^{\prime}$ UTR and to a TTC $\rightarrow$ TTT silent mutation in exon 1 . No single point mutation or $5^{\prime}$ end polymorphism was shown in healthy animals and in the remaining $50 \%$ of the clones from the affected calf. We hypothesise a possible pathogenic effect of the $5^{\prime}$ end-exon 1 polymorphism.
\end{abstract}

arthrogryposis / SMN / piemontese / cattle / cDNA

\section{INTRODUCTION}

In farm animals, the candidate gene approach can be a useful tool to identify disease genes, which afterwards can be included in a selection programme

\footnotetext{
* Correspondence and reprints
}

E-mail: maria.longeri@unimi.it 
analysis. The term arthrogryposis refers to a symptom complex characterised by congenital contractures. It consists of different degrees of flexion rigidity of the phalangeal, metacarpophalangeal, carpal and metatarsophalangeal joints. Arthrogryposis has been reported in man and in animals, having different origins.

Several forms have been reported to have a genetic origin in man [OMIM: http://bioinformatics.weizmann.ac.il/cards/], in farm animals and in pets [1,14], [OMIA: http://morgan.angis.su.oz.au/Databases/BIRX/omia/]. Recently, in a pedigree study, an autosomal recessive condition with congenital arthrogryposis was found in Suffolk lambs [3]. Inherited arthrogryposis has also been reported in cattle $[7,13]$.

In Italian Brown and in Holstein Friesian cattle, congenital contractures have been recorded and classified as spinal muscular atrophy (SMA) [20,21]. SMA is a subtype of inheritable human arthrogryposis named AMCN (arthrogryposis multiplex congenital, neurogenic). SMA and AMCN are caused in a wide number of cases by a gene named $S M N$. Several exon or gene duplications and deletions or point mutations of this gene have been recorded associated to arthrogryposis $[8,11,23]$. SMN protein plays the key role of shuttle in distributing, regenerating and assembling the spliceosome complex $[2,12]$. Moreover it is involved in transcription regulation, in mRNA axonal carrying and it shows an antiapoptotic role $[15,16]$.

In German Brown, SMN cDNA has been sequenced (GenBank\#AF035323) and mapped on chr. $20[4,18]$. An AluI PCR-RFLP polymorphism in exon 8 has been found [19] and sequence differences between SMA affected and control animals in exon 7 have been recorded [5]. Nevertheless, following linkage analysis of chromosome 20 by microsatellites, Eggen and co-workers excluded the entire chromosome 20 as the candidate region for SMA in cattle [5].

In Italy, the National Association of Piedmont Cattle - Piemontese (A. N. A. Bo. Ra. Pi) is committed to monitoring arthrogryposis cases and has been recording them since 1980. In a previous study on a 20 years old database, out of 438638 new-borns, 7912 individuals were affected (1.8\%). The incidence in females $(0.6 \%)$ and in males $(3.3 \%)$, and a higher presence of the defect in related animals suggests the hypothesis of a genetic disorder with incomplete penetrance in females [6]. By linkage analysis, using four microsatellites mapping close to the SMN locus on a family group showing the disorder, a Lod Score of 1.33 was recorded, suggesting the presence in the region of a gene affecting the character (data not shown).

In the present study, to identify the differences which could confirm the $S M N$ gene as possibly being involved in arthrogryposis of Piemontese, we cloned and sequenced the SMN cDNA of one arthrogryposis affected calf and one healthy Piemontese calf. 

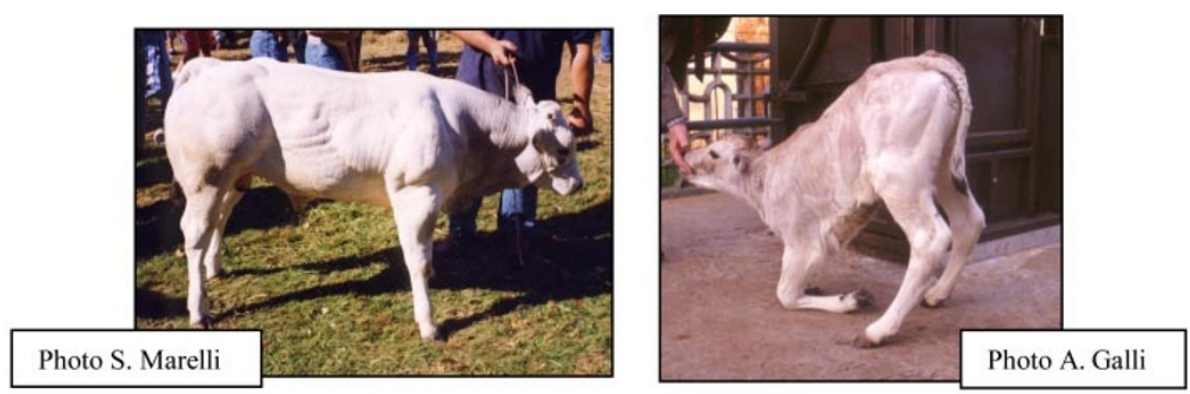

Figure 1. Healthy (left) and arthrogryposis affected (right) Piemontese calves.

\section{MATERIALS AND METHODS}

The animals were two unrelated Piedmont male calves, one showing a severe clinical form of arthrogryposis and one healthy (Fig. 1). The affected animal showed severe hyperflexion of both carpal joints and slight flexion of both metacarpal joints. Anamnesis did not report infections, toxic substances or lacks in the diet nor dystocia during delivery.

Total RNA from the spinal cord samples of the two animals were extracted with TRIzol ${ }^{\mathrm{TM}}$ (Gibco Life Technologies), according to the manufacturer's instructions. Total RNA was reverse transcribed by three different reactions, each corresponding to three different gene regions: $5^{\prime}$ UTR-exon 2, exons 1-6 and the exon 6-3'end. All the reactions were performed with commercial kits according to the manufacturer's instructions, using adapter/abridged primers and/or specific primers designed on the GenBank available sequence (\#AF035323). Thermalcycling was performed on a 9600 thermalcycler (Applied Biosystems): cDNA synthesis and amplification of the 5'UTR-exon 2 region was performed with the " $5^{\prime}$ RACE System for rapid amplification of cDNA ends ${ }^{\mathrm{TM}}$ " (Gibco Life Technologies), using three specific nested primers: $\operatorname{SMN} \alpha$ : 5'CAC ACC TAA GAG AAA ATC TGC TAA3' (on exon 3); $\operatorname{SMN} \beta$ : 5'GGT GCA TTT ACC CAG CTA CTA TCG C3' (on exon 3); SMNS $\gamma$ : 5'AGC TAC TAT CGC TTC AAT TGA TTT T3' (on exon 2) at a $55^{\circ} \mathrm{C}$ annealing temperature. cDNA synthesis and amplification of the exon 1-exon 6 region was performed with a ONE STEP RT/PCR System (Gibco Life Technologies), using the specific primers SMN1: 5'GGA GCC AGA GGA CTC GGT ACT GTT 3'; SMN4: 5'CCA GTA TGA TAA CCA CTC ATG TAC CAA GAG3' at a $63^{\circ} \mathrm{C}$ annealing temperature. cDNA synthesis and amplification of the exon 6$3^{\prime}$ end region was performed with the " 3 'RACE System for rapid amplification of cDNA ends ${ }^{\mathrm{TM}}$ ",(Gibco Life Technologies), using two specific nested primers: SMN $\sigma$ : 5'TCA GGT CTA AAC TTC AGT GGC CCA3' (on exon 5); $\operatorname{SMN} \varphi$ : $5^{\prime}$ CTC TTG GTA CAT GAG TGG TTA TCA TA3' (on exon 6) at a $60^{\circ} \mathrm{C}$ annealing temperature. 
PCR products were controlled on agarose gels, and the bands were eluted by GFX $^{\mathrm{TM}}$ PCR DNA and the Gel Band Purification Kit (Amersham Pharmacia Biotec). Purified products were then ligated to the pMOSBlue plasmid and cloned in Escherichia coli MOSBlue cells using the pMOSBlue blunt ended cloning kit (Amersham Pharmacia Biotec). Plasmids were extracted from positive colonies and both strands were sequenced using the ABI PRISM BigDye Terminator Cycle Sequencing Ready Reaction kit (Applied Biosystems) and the ABI Prism377 sequencer (Applied Biosystems).

One final control was performed by directly sequencing both strands of the 5'RACE PCR products before cloning. All sequence analyses were carried out using the BLAST ${ }^{\circledR}$ and Navigator ${ }^{\mathrm{TM}}$ sequence analysis packages (Applied Biosystems).

\section{RESULTS}

We cloned and sequenced 5'UTR-exon 6 SMN cDNA starting from mRNA extracted from spinal cord samples of one Piedmont calf showing a severe clinical form of arthrogryposis and of a normal Piedmont calf.

\subsection{Characterisation of the exon 1-exon 6 region}

RT-PCR were performed with a specific primer pair. The amplification generated one $780 \mathrm{bp}$ and one $650 \mathrm{bp}$ approximate length fragment on an affected and one $780 \mathrm{bp}$ length fragment on a healthy animal, respectively. Elution from agarose failed for the $650 \mathrm{bp}$ fragment, while both $780 \mathrm{bp}$ fragments were successfully purified and cloned into a plasmid. Both strands from 34 positive clones of the affected calf and seven positive clones of the healthy calf were sequenced.

A unique sequence was obtained, both in the healthy and affected calves, which showed only a silent $\mathrm{C}>\mathrm{A}$ substitution at the 5th codon in exon 6 (Proline) when compared to the GenBank available sequence (\#AF035323).

\subsection{Characterisation of the $5^{\prime}$ UTR-exon 2 region}

Three primers were designed to be used, coupled with commercial adapter primers, in a 5'RACE. Amplifications generated a single fragment both on the affected and healthy animals. The products were purified and cloned in E. coli with a plasmid vector.

Thirteen positive clones from the affected calf and fourteen positive clones from the healthy calf were sequenced for both strands, revealing high identity with the GenBank\#AF035323 sequence by BLAST ${ }^{\mathrm{TM}}$.

All healthy animal clones and seven out of the thirteen affected calf clones had an identical sequence (GenBank\#AF466193) (Fig. 2), with a 5'UTR end 


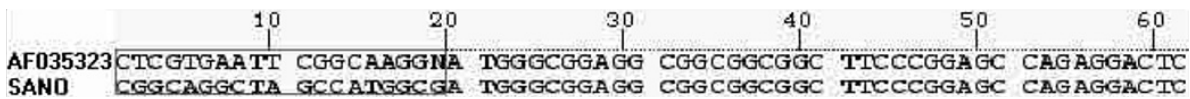

Figure 2. $5^{\prime}$ UTR and partial exon 1 of the $S M N$ gene. Alignment of consensus sequence of cDNA clones from a healthy calf (SANO) and Genbank\#AF035323. In the box: differences at $5^{\prime}$ UTR. By Navigator ${ }^{\mathrm{TM}}$ software (Applied Biosystems).

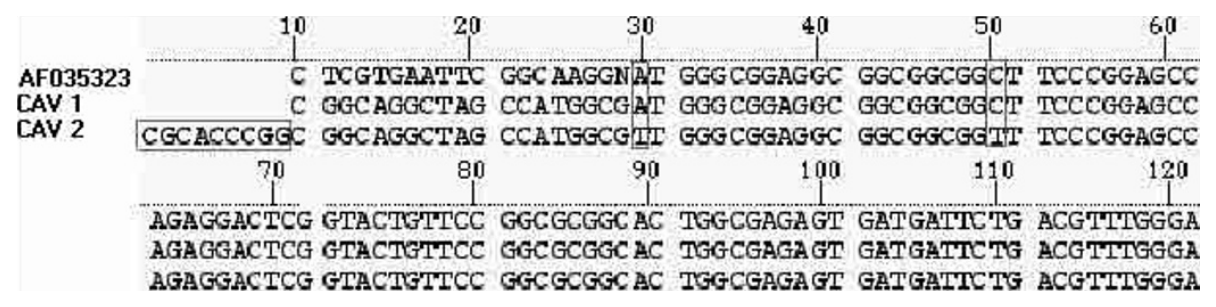

Figure 3. 5'UTR and partial exon 1 of the $S M N$ gene. Alignment of 2 different consensus sequences of cDNA clones (cav1 and 2) from the affected calf and Genbank\#AF035323. In the boxes: differences at 5'UTR and exon 1. By Navigator ${ }^{\mathrm{TM}}$ software (Applied Biosystems).

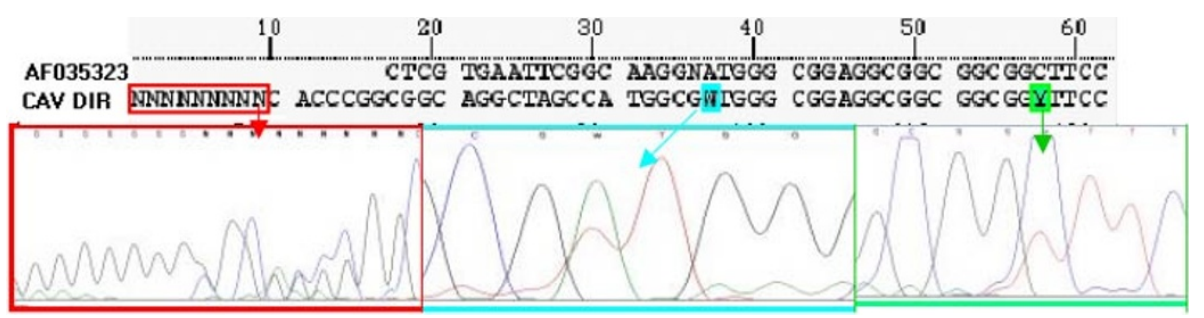

Figure 4. $S M N$ gene. Alignment of the direct sequence from the amplified cDNA of the affected calf(cavdir) and Genbank\#AF035323. In the boxes: differences at 5'UTR and exon 1. Electropherograms visualise the co-presence of both the "healthy" and the "affected" sequence in the PCR product before cloning.

showing 19 bp not aligning to the Pietrowsky et al. [18] available sequence (Fig. 3).

In the six other clones of the affected calf, a unique 243 bp sequence (GenBank\#AF466194) was recorded, showing a ATG > TTG Single Nucleotide Polymorphism (SNP) in exon 1, that determines a Met $>$ Leu aminoacid change (single point mutation M3L), a TTC $>$ TTT silent mutation in exon 1 and a 9 bp increased length at the $5^{\prime}$ UTR end (Fig. 3).

To verify the co-presence in the same PCR product of the two different sequences in the affected animal, the previously cloned 5'RACE products were directly sequenced. Direct sequencing confirmed that both patterns were present in the cDNA (Fig. 4). 


\subsection{Characterisation of the exon $6-3^{\prime}$ end region}

Two primers were designed to be used, coupled with commercial adapter primers, in a $3^{\prime}$ RACE. Amplifications generated six different fragments (of 200, 500, 600, 700, 900 bp approximate length), both from the affected and healthy animals. In agarose gel, the $200 \mathrm{bp}$ band appeared more intense in the affected animal, while the $600 \mathrm{bp}$ band appeared more intense in the healthy animal.

\section{DISCUSSION}

The Piemontese is an autochthonous Italian breed. It produces carcasses of considerable value, which, thanks to the meat potential and the low fat rates, rank in the highest categories of the International classification. In Piemontese, arthrogryposis is a quite high incidence defect, which determines economic losses in terms of management, reduction of productive life of the animal and loss in carcass weight at slaughter. Since a major incidence in males and in related animals is recorded [6], it is assumed to be a hereditary defect. Several arthrogryposis forms of genetic origin have been recorded in many vertebrates and in cattle. We identified the SMN gene as being possibly involved in the defect of the Piemontese, since it has been demonstrated in a similar form of human arthrogryposis (SMA).

By cloning and sequencing SMN cDNA of one arthrogryposis affected and one normal calf, we recorded some differences in the gene sequences obtained.

The presence in agarose gel of one and two fragments in the healthy and affected animal respectively was shown by amplifying the exon 1-exon 6 SMN cDNA region. Unfortunately, the lighter fragment was not sequenced, but it is possible to presume the presence of SMN alternative spliced molecules, as previously described in man [9] and cattle [6], associated or not to a gene duplication, as in man [2].

The RACE of the 5'UTR-exon 2 region amplified a single band in both animals, but two different sequences were recorded.

The first sequence was identical in the healthy animal and in half the clones from the affected animal, with $19 \mathrm{bp}$ not aligning to the Pietrowsky et al. available sequence [18] (GenBank\#AF466193). In this motif, it is possible to presume a two codon shift towards the 5'end of the starting atg codon in comparison to the Pietrowsky et al. sequence which could, in turn, create a protein sequence starting MAM instead of M, as in other species (man GenBank\#XM017073; mice GenBank\#U77714; Zebrafish GenBank\#AF083557). The $9 \mathrm{bp}$ increased length could be due to the polymorphism of the same gene or to a gene duplication. A larger $5^{\prime}$ end could destabilise the mRNA in the region, which drives the ribosomal units assembly. 
The second sequence from the affected animal clones showed three differences from the healthy animal sequence all linked in exon 1: a ATG > TTG single nucleotide polymorphism (SNP) in exon 1, a $5^{\prime}$ extended end and a TTC $>$ TTT silent mutation (GenBank\#AF466194).

The SNP ATG > TTG determines a Met $>$ Leu aminoacid change (single point mutation M3L). Similarly, an exon 1-A2G mutation has been described as being associated to a $5^{\prime}$ UTR polymorphism in children affected by arthrogryposis ([17], http://www.faseb.org/genetics/ashg99/fl663.htm). Exon 1 is the anchor target for the protein SIP1 (SMN interacting protein 1) that creates a complex with SMN necessary for the splicing process [22]. Therefore, it is possible to assume a pathogenic effect of exon 1 mutations in both man and cattle, since they are located in the SMN region where SP1 interacts to form the spliceosoma, a fundamental complex for the cell splicing mechanism. Difficulties in SIP1-SMN binding could be an obstacle to mRNA maturing.

The RACE of the exon 6-3'end generated different fragments both from affected and healthy animals which could confirm the variability of the $7-3^{\prime}$ end region of the exon, already partly described in cattle [18]. In man, the variability in this region is recorded as being associated to the pathogenesis of the disorder [10].

Some evidence on the genetic origin of arthrogryposis in Piemontese has been stated in previous breeding association data analysis, but several aspects still have to be clarified, such as the anatomo-histopathological and clinical description.

Our results on $S M N$ as a gene affecting the disorder are preliminary since we analysed only two unrelated animals, not fully informative on the SMN polymorphism in the population. Still, in a previous study, we demonstrated the presence in several Piedmont calves of SMN mRNA showing a different length, produced by alternative splicing or gene duplication [24]. The presence of a polymorphic sequence in $5^{\prime}$ end cDNA should be analysed also in related animals with different phenotypes and in different breeds to better clarify if discrepancies between present and previously reported data on the association of $S M N$ with arthrogryposis [5] are due to differences between breeds in the pathogenic path of the symptom complex.

Nevertheless, the present study shows some promising indication on the genetic basis of bovine arthrogryposis and indicates some polymorphisms that could compromise the efficiency of the SMN molecule.

\section{ACKNOWLEDGEMENTS}

We thank A. N. A. Bo. Ra. Pi. (Carrù-CN) for providing animals and studbook database access. This research was supported by R. A. I. Z. (N. RZ-271). 


\section{REFERENCES}

[1] Blazej R.G., Mellersh C.S., Cork L.C., Ostander E.A., Hereditary canine spinal muscular atrophy is phenotypically similar but molecularly distinct from human spinal muscular atrophy, J. Hered. 89 (1998) 531-537.

[2] Coovert D.D., Le T.T., McAndrew P.E., Strasswimmer J., Crawford T.O., Mendell J.R., Coulson S.E., Androphy E.J., Prior T.W., Burghes A.H., The survival motor neuron protein in spinal muscular atrophy, Hum. Mol. Genet. 6 (1997) 1205-1214.

[3] Doherty M.L., Kelly E.P., Healy A.M., Callanan J.J., Crosby T.F., Skelly C., Boland M.P., Congenital arthrogryposis: an inherited limb deformity in pedigree Suffolk lambs, Vet. Record 24 (2000) 748-753.

[4] Eggen A., Masabanda J., Pfister-Genskow M., Fries R., Bishop M.D., The bovine survival motor neuron gene $(S M N)$ maps to bovine chromosome 20q14, Anim. Genet. 29 (1998) 408-409.

[5] Eggen A., Pfister-Genskow M., Boichard D., Fries R., Bishop M.D., Exclusion of bovine chromosome 20 as candidate region for Spinal Muscular Atrophy (SMA), Anim. Genet. 29 (1998) 35.

[6] Galli A., Zanotti M., Bongioni G., Del Bo L., Bona M., Aleandri R., Longeri M., Arthrogryposis in Piedmontese cattle breed: a genetic analysis, in: Proceedings of the 27th International Conference on Animal Genetics, 22-26 July 2000, University of Minnesota, Minneapolis, MN, p. 87.

[7] Goonewardens L.A., Berg R.T., Arthrogryposis in Charolais cattle - a study on gene penetrance, Ann. Génét. Sél. Anim. 8 (1976) 493-499.

[8] Hoffmann Y., Lorson C.L., Stamm S., Androphy E.J., Wirth B., Htra2-beta1 stimulated an exonic splicing enhancer and can restore full-lenght SMN expression to survival motor neuron 2 (SMN2), Proc. Natl. Acad. Sci. USA 97 (2000) 9618-9623.

[9] Lefebvre S., Burglen L., Reboullet S., Clermont O., Burlet P., Viollet L., Benichou B., Cruaud C., Millasseau P., Zeviani M., Identification and characterization of a spinal muscular atrophy-determining gene, Cell 80 (1995) 155-165.

[10] Lorson C.L., Strasswimmer J., Yao J.M., Baleja J.D., Hahnen E., Wirth B., Le T., Burghes A.H., Androphy E.J., SMN oligomerization defect correlates with spinal muscular atrophy severity, Nat. Genet. 19 (1998) 63-66.

[11] Lorson C.L., Hahnen E., Androphy E.J., Wirth B., A single nucleotide in the SMN gene regulates splicing and is responsible for spinal muscular atrophy, Proc. Natl. Acad. Sci. USA 96 (1999) 6307-6311.

[12] Mourelatos Z., Abel L., Yong J., Kataoka N., Dreyfuss G., SMN interacts with a novel family of hnRNP and spliceosomal proteins, EMBO 20 (2001) 5443-5452.

[13] Nawrot P.S., Howell W.E., Leipold H.W., Arthrogryposis: an inherited defect in newborn calves, Aust. Vet. J. 56 (1980) 359-364.

[14] Nes N., Lomo O.M., Bejerkas I., Hereditary lethal arthrogryposis (muscle contracture) in horse, Nord. Vet. Med. 34 (1982) 425-430.

[15] Pagliardini S., Giavazzi A., Setola V., Lizier C., Di Luca M., DeBiasi S., Battaglia G., Subcellular localization and axonal transport of the survival motor neuron $(S M N)$ protein in the developing rat spinal cord, Hum. Mol. Genet. 9 (2000) 47-56. 
[16] Pancani I., Cristofori F., Sartore G., Aria G., Further studies on congenital arthrogryposis in calves of the Piedmont breed, in: $9^{\mathrm{e}}$ Congrès International sur les Maladies du Bétail, Paris, 1976, pp. 217-223.

[17] Parson D.W., Mc Andrew P.E., Iannaccone S.T., Mendell JR., Burghes A.H., Prior T.W., Intragenic telSMN mutations: frequency, distribution, evidence of a founder effect, and modification of the spinal muscular atrophy phenotype by cenSMN copy number, Am. J. Hum. Genet. 63 (1998) 1712-1723.

[18] Pietrowsky D., Goldammer T., Meinert S., Shwerin M., Foerster M., Description and physical localisation of the bovine survival of motor neuron gene $(S M N)$, Cytogenet. Cell Genet. 83 (1998) 39-42.

[19] Pietrowsky D., Kemter J., Medugorac I., Goldammer T., Foerster M., An AluI PCR-RFLP in the bovine survival motor neuron gene (SMN), Anim. Genet. 30 (1999) 168.

[20] Pozzatti A., SMA, Atrofia Muscolare Spinale, La razza bruna (2002) 23-25.

[21] Pumarola M., Anor S., Majo N., Borras D., Ferrer I., Spinal Muscular Atrophy in Holstein-Friesian calves, Acta neuropathologica 93 (1997) 178-183.

[22] Strasswimmer J., Lorson C.L., Breiding D.E., Chen J.J., Le T., Burghes A.H., Androphy E., Identification of survival motor neuron as a transcriptional activator-binding protein, Hum. Mol. Genet. 8 (1999) 1219-1226.

[23] Vitali T., Sossi V., Tiziano F., Zappata S., Giuli A., Paravatou-Petsoa M., Neri G., Brahe C., Detection of the survival motor neuron $(S M N)$ genes by FISH: further evidence for a role for SMN2 in the modulation of diseases severity in SMA patients, Hum. Mol. Genet. 8 (1999) 2525-2532.

[24] Zanotti M., Bongioni G., Galli A., Longeri M., Del Bo L., Bona M., Aleandri R., Basi genetiche dell' artrogrifosi nel bovino Piemontese, in: 34e Simposio Internazionale di Zootecnia. S. I. P. Zoo su Strumenti innovativi per la ricerca avanzata nelle produzioni animali, 1999, Milano, pp. 367-375.

To access this journal online: www.edpsciences.org 